\title{
Volatile organic compounds: instrumental and canine detections link an individual to the crime scene
}

Vera Filetti ${ }^{1 \dagger}$, Giulio Di Mizio ${ }^{2 \dagger}$, Marcello Rendine ${ }^{3}$, Palmira Fortarezza ${ }^{4}$, Pietrantonio Ricci, ${ }^{3,5}$, Cristoforo Pomara ${ }^{6,9^{*}}$ (D), Giovanni Messina ${ }^{3}$, Irene Riezzo ${ }^{3}$, Christian Zammit ${ }^{7}$, Antonietta Messina $^{8}$, Monica Salerno ${ }^{6 \dagger}$ and Francesco Sessa ${ }^{3 \dagger}$

\begin{abstract}
Background: Whenever a crime is committed, forensic personnel are requested to collect every kind of evidence to establish the relationship between the suspects and the crime. When any evidence is accidentally destroyed or not found, there is one type of latent evidence that is always deposited at the crime scene: unique human scent. Recently, the use of trained canines to detect selective human scent at a crime scene has increased. To consolidate this kind of evidence, it is essential to have an exact knowledge and an awareness of the chemical signature of the volatile compounds that could indicate the presence of the alleged offender at the crime scene.

This experimental study aims to detect the volatile organic compounds (VOCs) released from subjects who handled scent-articles to imprint their odor on. After handling, each scent-article was wrapped in sterile and VOC-free cotton gauzes for $48 \mathrm{~h}$ for secondary transfer. VOCs were detected by headspace/solid-phase microextraction-gas chromatography/mass spectrometry (HS/SPME-GC/MS) and well-trained dogs, at different time points (up to 15 days). Furthermore, the possibility of further DNA detection after contact was also investigated to propose a novel approach able to identify a subject from this latent forensic trace.

Results: Data show that inter-individual human scent composition includes different VOCs, but dogs were able to discriminate the individual who touched the object at the crime scene. The dog training procedure showed excellent sensitivity (between 99.48 and 100\%) and specificity (between 60 and 100\%), having a positive predictive value (PPV) ranging between 97.94 and 100\% and a negative predictive value (NPV) ranging between 85.71 and 100\%. Preliminary work on DNA analysis released after contact yielded positive results, even if further studies are necessary, expanding the same experimentation to a larger sample with the aim of obtaining a statistically significant result.
\end{abstract}

Conclusion: Data show that human scent is a good source of VOCs and a good target for canine training. The welltrained dog represents a specialized biological device able to discriminate personal human odor from any contaminants in the mixture detected by instrumental analysis. Furthermore, this study proposes the use of human scent as a forensic latent trace for DNA profiling.

Keywords: Forensic science, Volatile organic compounds, Human scent, Gas chromatography/mass spectrometry, Dog training, DNA analysis

\footnotetext{
*Correspondence: cristoforo.pomara@unifg.it

Monica Salerno and Francesco Sessa shared last authorship.

†Vera Filetti and Giulio Di Mizio contributed equally to this work.

${ }^{6}$ Section of Legal Medicine, "F. Ingrassia" Department, University of Catania,

Catania, Italy

${ }^{9}$ Department of Medical and Surgical Sciences and Advanced Technologies

GF Ingrassia, University of Catania, Via S. Sofia 78, 95123 Catania, Italy

Full list of author information is available at the end of the article
} 


\section{Background}

Human scent consists of a mixture volatile organic compounds (VOCs) released from the body. VOCs are chemical compounds such as aliphatic, aromatic and chlorinated hydrocarbons, aldehydes, terpenes, alcohols, esters, and ketones. These are defined as organic compounds, which at $293.15 \mathrm{~K}\left(20{ }^{\circ} \mathrm{C}\right)$ have a vapor pressure of $0.01 \mathrm{kPa}$ or higher (Waring and Wells 2015). This characteristic of passing easily to the aeriform state at room temperature and ambient pressure makes them perceptible to smell.

"Odorology" is the set of investigative methods to extract and analyze human scent to establish its association with an object/subject or if the subject had handled an object (Pomara et al. 2015; Maglietta et al. 2017; Sessa et al. 2018; Ferrara et al. 2019; De Simone et al. 2019). The importance of this application in the forensic field is the possibility to link a suspect to a crime scene. Moreover, it is very useful in cases of missing persons when "odorology" could be very important for the investigation. Both cases involve the use of dogs to target a specific scent. In the first case, detailed sampling is carried out, comparing the human scent found at the crime scene, with the suspect's scent. In the second case, the dog follows the trace of human scent by comparing the smell of a target with the missing person's scent (Marchal et al. 2016). In one case, the trace is attributed to the author of the crime, while in the other the victim's trace is followed. Two operational systems correlated to protocols for human scent identification in forensic field are generally used in many countries (Schoon and Haak 2002).

In various studies, the VOCs of human scent were detected after direct contact between the palms of the subject's hands and absorbent gauzes (Curran et al. 2007; Colón-Crespo et al. 2017), or glass beads (Doležal et al. 2017). Other studies reported the use of a non-contact device, known as the Scent Transfer Unit 100 (STU$100)$, to detect the VOCs from an object or subject (Caraballo et al. 2016; DeGreeff et al. 2011).

The first experiments on human scent stored in containers were carried out in the Soviet Union in the 1960s. Subsequently, this specialty was developed in the German Democratic Republic. Based on the Russian experience, in 1989, an "Odorology Laboratory" was established in Cuba. To date, "odorology" is used in Cuba, Denmark, Holland, Belgium, Sweden, Germany, Hungary, Argentina, and Poland (Gajjar and Kasting 2014; Intarakumhaeng et al. 2018).

Human skin VOCs are aliphatic hydrocarbons, aldehydes, ketones, alcohols, fatty acids, esters (Curran et al. 2005; Haze et al. 2001; Spagnolo et al. 2018; Bernier et al. 2000; Munk et al. 2000; Zeng et al. 1991, 1996), steroids, unsaturated acids (Kanda et al. 1990; Messina et al. 2018), aromatic hydrocarbons, amides, and amines
(Curran et al. 2007; Prada and Furton 2008). Their composition is influenced by genetics, the environment, daily activities, diet, and physiological secretions. Furthermore, various factors, such as humidity, temperature, bacterial flora, $\mathrm{pH}$ of the skin surface (Pandey and Kim 2011; Sperandeo et al. 2018), illnesses, the onset of puberty, and menstrual cycle in females (Ensminger et al. 2010) contribute to the unique human scent.

Several studies have been conducted studying the VOCs released from human skin. However, to the best of our knowledge, no studies have been performed on secondary transfer linked to human scent. In other words, even if the opportunity to transfer biological traces indirectly has been well described, no references have been found related to human scent. Indeed, secondary transfer is well described as the event that occurs when any biological trace is deposited on an item or subject, and then transferred to another item or person (Goray et al. 2010). A biological sample that has been transferred multiple times, if detectable, will often appear as components of complex DNA profiles (Wickenheiser 2002; Ladd et al. 1999).

\section{Aim of the work}

This experimental study aimed to detect the VOCs released from subjects that stimulate canine olfactory discrimination alerts, using gas chromatography-mass spectrometry (GC-MS) after secondary transfer. Thus, the main goals were to analyze the chemical composition of human scent, discriminating it from contaminants and determining the scientific basis for dog training. Finally, DNA analysis was performed to verify if it is possible to obtain a profile that could be useful for the identification after a secondary transfer.

\section{Methods}

\section{Preparation of human scent samples}

Human scent samples were collected from four Caucasian subjects (two males and two females) between 18 and 50 years old. The exclusion criteria for subject recruitment were the presence of skin diseases or disorders. All subjects gave written informed consent in accordance with the latest version of the declaration of Helsinki. The protocol was approved by the Research Committee (University of Foggia). The subjects washed their hands with water, using the same antiseptic soap. Subsequently, the hands were dried off naturally, without contact with any object or other subject. Then each subject handled two scent-articles for $5 \mathrm{~min}$ to imprint their odor on, for a total of eight items. The scent-articles were made up of different substrates in groups of two: ceramic, plastic, treated wood, and wax. Different scent-articles were used in the experimental design to verify if human scent could be sampled by the different substrates at the experimental 
conditions. After handling, each scent-article was wrapped in ten sterile and VOC-free cotton gauzes $(10 \times 10 \mathrm{~cm})$ for $48 \mathrm{~h}$, for secondary transfer. The gauzes did not affect the results because they are inert and VOC-free. At each time $(0,5,10,15$ days), a new gauze was analyzed using the headspace/solid-phase microextraction-gas chromatography/mass spectrometry (HS/SPME-GC/MS) method to verify the background.

After $48 \mathrm{~h}$, the gauzes were removed. Ten gauzes were prepared and only nine were used for the successive phases. Each gauze for GC/MS analysis was divided into two parts and inserted into clear glass vials closed with a sterile and VOC-free film for subsequent analysis in duplicate. This sampling method was used to preserve the headspace of each sample. The gauzes for the following DNA profiling were inserted into vials previously pretreated with UV light for $20 \mathrm{~min}$. They were subdivided into three groups. The samples were all prepared at the same time (time 0 of the experiment) for a total of 98 samples (32 gauzes in duplicate for GC-MS detection, 32 for canine training, 2 gauzes for DNA profiling). The first group (four gauzes for each scent-article) was used to detect the VOCs using HS/SPME-GC/MS; the second group (four gauzes for each scent-article) was presented to a dog (Labrador Retriever) to sniff and stimulate discriminating alerts during the training procedure described below. These gauzes were placed in $40 \mathrm{ml}$ clear glass vials closed with a sterile and VOC-free film. The vials were stored at a room temperature of $22{ }^{\circ} \mathrm{C}$ and relative humidity of $45 \%$.

The third group (one gauze from two scent-articles) was used for DNA extraction. A negative control was taken for each gauze before experimentation and each sample was analyzed in duplicate. Two buccal swabs (called "MAN A" and "MAN B") were taken from the subjects who participated in this study. All the samples for the genetic analysis were stored at $-20{ }^{\circ} \mathrm{C}$.

\section{SPME-GC/MS analysis}

The gauzes were analyzed at different extraction times $(0,5,10$, and 15 days $)$ in duplicate. At each time point, a "white fiber" (PDMS/DVB) with empty vial and a "white sample" with new sterile and VOC-free cotton gauze were performed to verify the siloxane peaks and background. The siloxane peaks that resulted from the SPME fiber coating and from the column were removed. The first extraction of the gauzes was assessed at time 0 of the experiment. The SPME extractions were repeated every 5 days for 15 days. For all samples, four analysis times were investigated.

After several optimization tests, SPME extraction time and temperature and GC method parameters were chosen in order to obtain a chromatogram with an optimal signal to noise $(\mathrm{S} / \mathrm{N})$ ratio. Polydimethylsiloxane/

divinylbenzene (PDMS/DVB) $65 \mu \mathrm{m}$ fiber was exposed to the headspace of the vials containing the gauzes to extract the VOCs at the different times of analysis with an incubation time of $10 \mathrm{~min}$ at $40{ }^{\circ} \mathrm{C}$. The samples were analyzed in a Thermo Scientific Trace GC Ultra with a DSQ II mass selective detector (Thermo Fisher Scientific, Waltham, MA, USA). The column used was a $30 \mathrm{~m} \times 0.25 \mathrm{~mm}$ ID, $0.25 \mu \mathrm{m}$ film thickness DB-5-MS. Helium was the carrier gas, flow controlled at $1.0 \mathrm{ml} / \mathrm{min}$. The VOCs were desorbed in the injection port of the GC using an inlet temperature set at $200{ }^{\circ} \mathrm{C}$. The 28 -min GC method consists of three steps: at the first step, the temperature of $50{ }^{\circ} \mathrm{C}$ was maintained for $3 \mathrm{~min}$, followed by an increment of $10^{\circ} \mathrm{C} / \mathrm{min}$ up to $200^{\circ} \mathrm{C}$, and ending with a 10 -min hold. The quadrupole mass analyzer was operated in the electron ionization (EI) mode and scanned over a mass range of $m / z 50-650$ in full-scan mode (Table 1 ).

After extraction and analysis of the collected human scent samples, the National Institute of Standards and Technology (NIST) mass spectral library and the extracted ion chromatograms were used to identify the compounds in the headspace of the samples. The qualitative method was based on a previously reported GC-MS method that analyzed human VOCs (Urbanová et al. 2012; Stránský et al. 2006; Doležal et al. 2017; Vass 2012; Hoffman et al. 2009; Rendine et al. 2018).

\section{Dog training for human scent discrimination}

In this experimental model, two trained Labrador Retrievers were used. All experimental procedures were

Table 1 Analytical parameters used for VOCs extraction, separation, and detection by HS/SPME-GC/MS

Gas chromatography/head space

Fiber

Incubation time

Constant incubation

temperature

Column

Carrier gas

Constant flow

Inlet temperature

Ramp

Hold time

Oven run-time

Mass detector

Ionization mode

Full-scan mass range
Polydimethylsiloxane/ divinylbenzene $(65 \mu \mathrm{m})$

10 min

$40^{\circ} \mathrm{C}$

DB-5-MS $(30 \mathrm{~m} \times 0.25$ $\mathrm{mm}$ ID, $0.25 \mu \mathrm{m})$

Helium

$1.0 \mathrm{ml} / \mathrm{min}$

$200^{\circ} \mathrm{C}$

$50{ }^{\circ} \mathrm{C}$ for $3 \mathrm{~min}$

$10^{\circ} \mathrm{C} /$ min until $200^{\circ} \mathrm{C}$

10 min

$28 \mathrm{~min}$ 


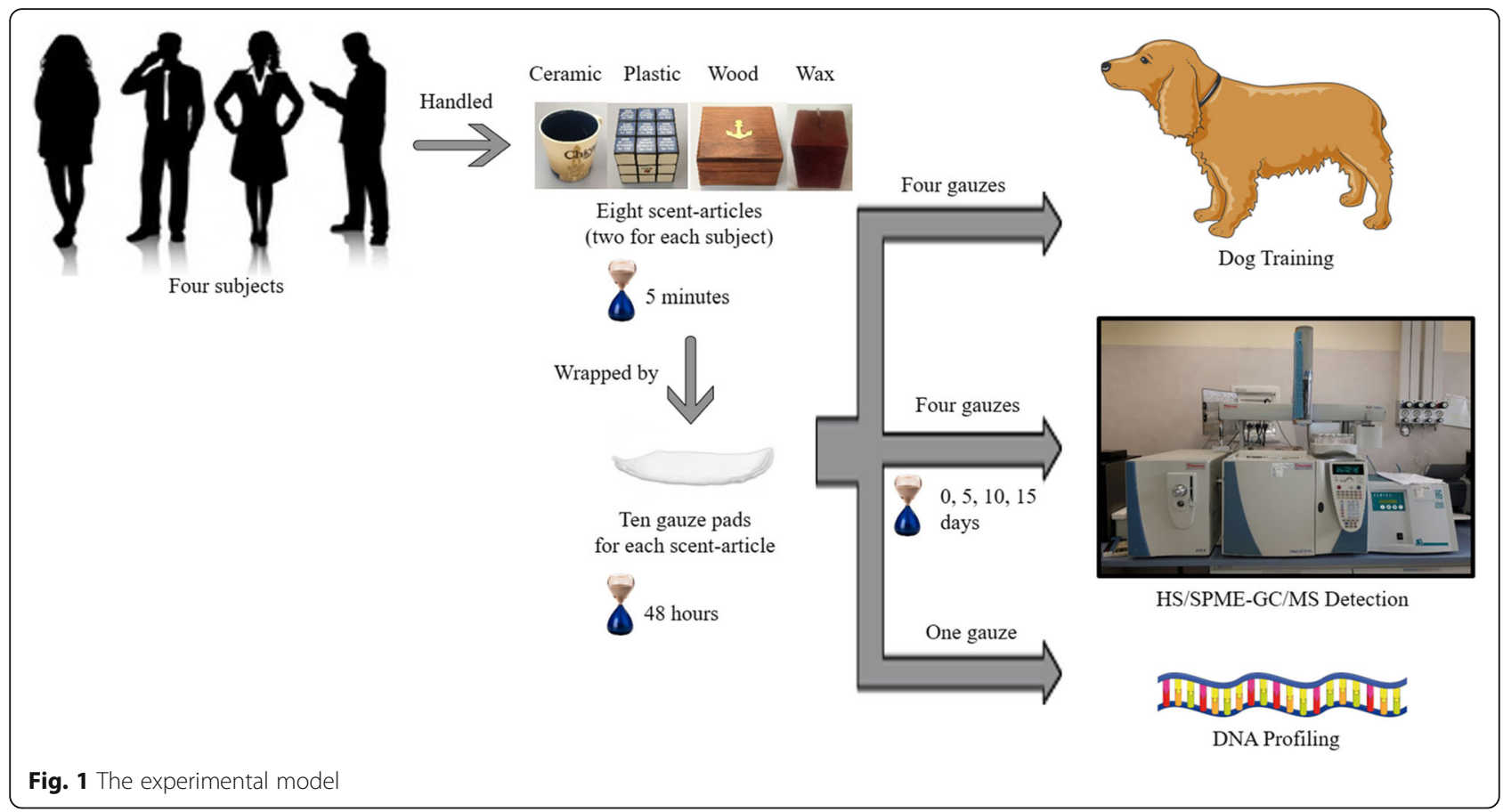

performed in strict accordance with the Italian and EU regulation on animal welfare and were previously approved by the Animal Research Committee of the University of Foggia. The gauzes were presented to the first $\mathrm{dog}$, after having being in contact with the scent-articles for $48 \mathrm{~h}$. Two hundred trials were carried out for each scent-article (50 trials with each gauze for four sampled gauzes). The subjects were asked to position themselves in a straight line in front of the dog with its handler (Riezzo et al. 2014). After smelling the gauzes, the dog approached the subjects with its handler. The dog sat in front of the corresponding subject whenever it matched the scent. Following each correct choice, the handler rewarded the dog with a treat. After an incorrect choice, or if the dog did not make a choice at all, the dog was not rewarded. The standard protocol for trained dogs changes based on the type of training. In all cases, you have to reward the dog with a cookie or with its favorite toy because the dog associates the prize with a successful action. A second dog (Labrador Retriever) was used to repeat the protocol and confirm the results of the first (Fig. 1).

\section{DNA analysis}

DNA extraction of the reference samples (buccal swabs called "MAN A" and "MAN B") was obtained with QIAmp DNA mini kit (Qiagen, Venlo, the Netherlands). The gauzes were sampled with the cut-out technique;

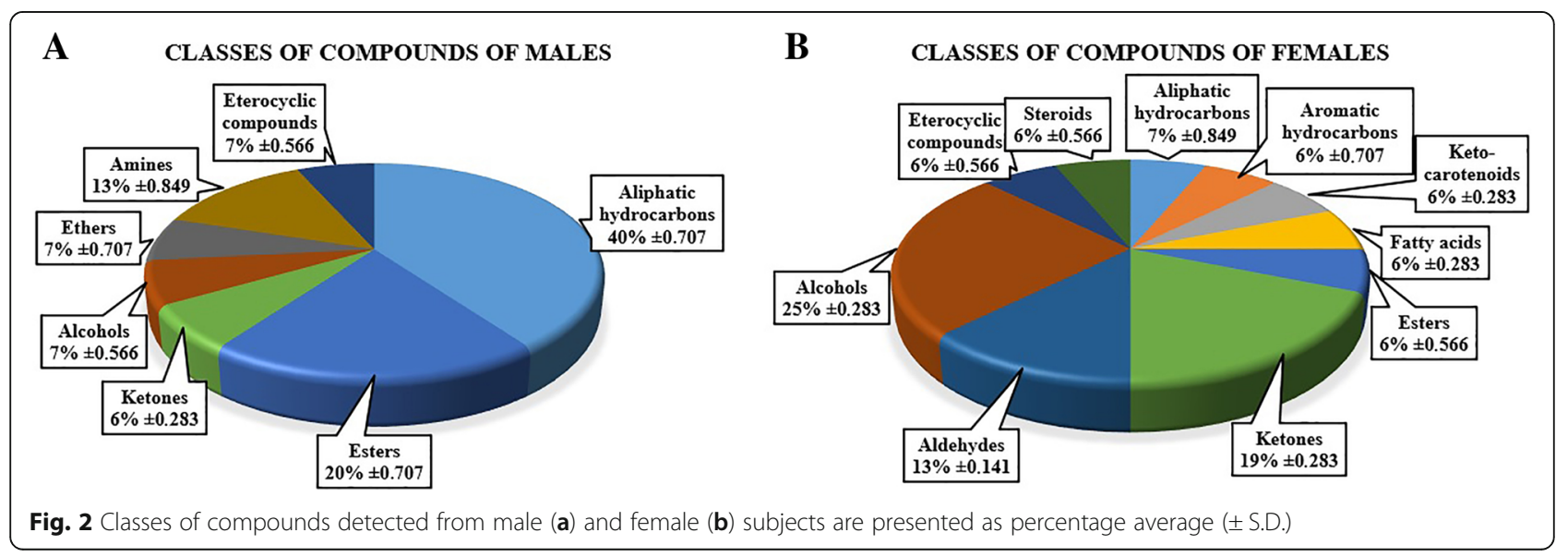


Table 2 The chemical composition of the human scent samples of the four subjects

\begin{tabular}{|c|c|c|c|c|}
\hline Compounds & Man A & Man B & Woman A & Woman B \\
\hline Canthaxanthin (keto-carotenoid) & & & & $\checkmark$ \\
\hline 2,2-Dimethoxy-ethanol (alcohol) & $\checkmark$ & & $\checkmark$ & \\
\hline Protoporphyrin IX dimethylester (ester) & & & & $\checkmark$ \\
\hline Tridecane (aliphatic hydrocarbon) & & $\checkmark$ & & \\
\hline $\begin{array}{l}\text { Ethanone, 2-(4-hydroxy-5,7-dimethylpyrido[2,3-d]pyrimidin-2-ylsulfanyl)- } \\
\text { 1-(4-(eterocyclic compound) }\end{array}$ & & & & $\checkmark$ \\
\hline Benzo [b] thiophene, 6-methyl (eterocyclic compound) & $\checkmark$ & & & \\
\hline Propane (aliphatic hydrocarbon) & $\checkmark$ & & & \\
\hline Ethylhexanol (alcohol) & & & & $\checkmark$ \\
\hline Decane (aliphatic hydrocarbon) & & $\checkmark$ & & \\
\hline 14-Octadecenal (aldehyde) & & & & $\checkmark$ \\
\hline Linalyl alcohol (alcohol) & & & & $\checkmark$ \\
\hline Camphor (ketone) & & & & $\checkmark$ \\
\hline Octadecane, 1,1-dimethoxy (ether) & $\checkmark$ & & & \\
\hline Silanamine, N-phenyl (amine) & & $\checkmark$ & & \\
\hline Sulfurous acid, cyclohexylmethyl hexyl ester (ester) & $\checkmark$ & & & \\
\hline Cyclohexane, 1,4-dimethyl-2-octadecyl (aliphatic hydrocarbon) & $\checkmark$ & & & \\
\hline Naphthalene, decahydro-2,6-dimethyl-3-octyl (aromatic hydrocarbon) & & & $\checkmark$ & \\
\hline 1,4-Benzenediol, 2,5-dimethyl (alcohol) & & & & $\checkmark$ \\
\hline 2-Thiopheneacetic acid, undec-10-enyl ester (ester) & $\checkmark$ & & & \\
\hline 3-Dodecylcyclohexanone (ketone) & $\checkmark$ & & & \\
\hline Dodecane (aliphatic hydrocarbon) & $\checkmark$ & & & \\
\hline Cedr-8-ene (terpene) & & & & $\checkmark$ \\
\hline Thujopsene (terpene) & & & & $\checkmark$ \\
\hline Undecane (aliphatic hydrocarbon) & $\checkmark$ & & & \\
\hline Octadecadienoic acid (fatty acid) & & & $\checkmark$ & \\
\hline Tetrahydrocortisone (steroid) & & & $\checkmark$ & \\
\hline 1,4-Naphthoquinone (ketone) & & & $\checkmark$ & \\
\hline 9-n-Hexylheptadecane (aliphatic hydrocarbon) & & & & $\checkmark$ \\
\hline Propanoic acid, dimethylester (ester) & & $\checkmark$ & & \\
\hline Benzaldehyde (aldehyde) & & & $\checkmark$ & \\
\hline Beta- Methylionone (ketone) & & & & $\checkmark$ \\
\hline Methyl-3-phenylpyridine (amine) & & $\checkmark$ & & \\
\hline
\end{tabular}

therefore, a small portion of each gauze previously in contact with the scent-article was cropped to proceed with DNA extraction. Each sample was analyzed using the double-blind method. The DNA was obtained using the QIAmp DNA Investigator kit (Qiagen, Venlo, Netherlands) following the protocol used for paper or similar material. The AmpFlSTRIdentifiler PCR Amplification kit (Applied Biosystems, Foster City, CA, USA), which simultaneously amplifies 15 markers, was utilized. A negative control of the PCR reaction and a positive control (control DNA 9947A) were added as a quality control. The fragments were determined by capillary electrophoresis through the ABI Prism 3130 Genetic Analyzer (AppliedBiosystems, Foster City, CA, USA) and the GeneMapper ID v.4.0 software, which allows assignment of alleles, comparing them with an allelic ladder.

\section{Results and discussion}

The human scent samples were extracted at four different times: $0,5,10$, and 15 days. Over 30 VOCs were identified with different functional groups. Only VOCs that had been previously cited in the literature as 


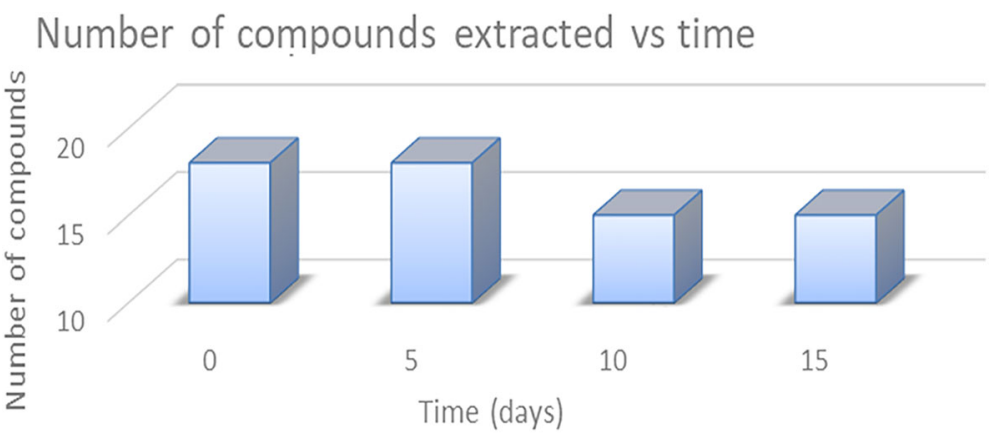

Fig. 3 Number of compounds extracted from fresh and aged samples

originating from human specimens were used in the analysis of our samples.

The chemical compounds detected in males' scent included seven different functional groups: aliphatic hydrocarbons, esters, amines, alcohols, ethers, heterocyclic compounds, and ketones (Fig. 2a). The chemical compounds detected in the females' samples included ten different classes: alcohols, ketones, aliphatic hydrocarbons, aldehydes, esters, steroids, heterocyclic compounds, fatty acids, keto-carotenoids, and aromatic hydrocarbons (Fig. 2b). Both graphs contain the average percentage of the compounds $( \pm$ S.D.) of the subjects detected within each gender. Aliphatic hydrocarbons and alcohols were found to be the most prevalent, contributing $40 \%$ and $22 \%$ of scent-articles from males and females, respectively. 2,2-Dimethoxy-ethanol was detected both in males and females.

Table 2 shows the complete experimental data on the chemical composition of the human scent samples of the four subjects involved in the study (two males and two females) and the differences in composition depending on the individual. Inter-individual human scent composition includes different VOCs, independently of sex.

Furthermore, 2,2-dimethoxy-ethanol was detected both in fresh (time $=0-5$ days) and in old samples (time $=10$ 15 days). As previously described, the probability that compounds with greater volatility are detected is higher for the fresher scent-articles with respect to older samples. In older samples, these compounds could evaporate or be transformed by microbial action (Curran et al. 2007), becoming undetectable. Loss by evaporation has been supported anecdotally from the behavior of trained dogs when following a scent trail. A fresh trail is followed with the head in an upright position suggesting that more volatile compounds are being utilized, whereas an old trail is followed with the nose to the ground suggesting that less volatile compounds are being utilized (Curran et al. 2007). In agreement with this theory, in this study, 18 human

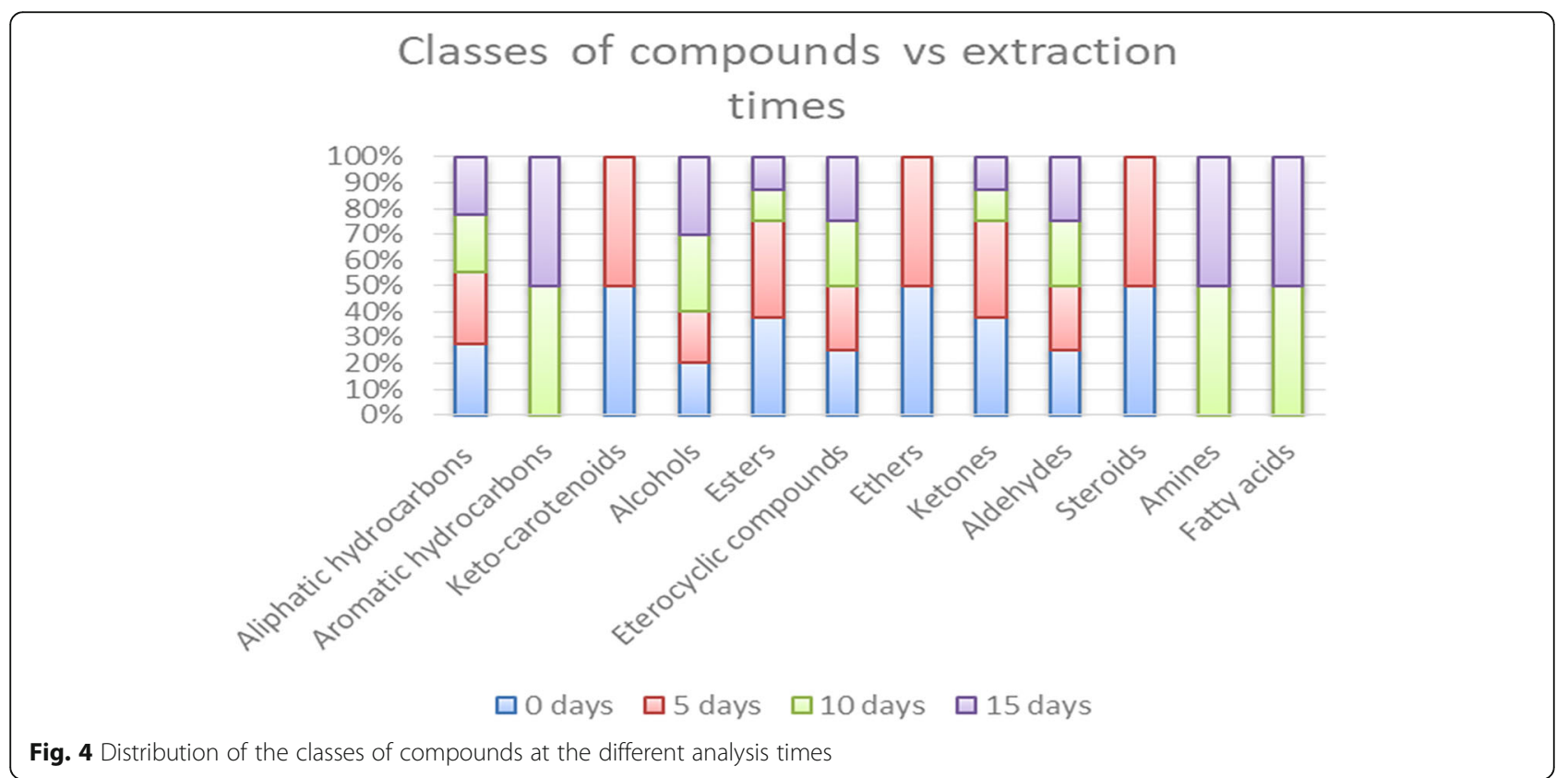


scent VOCs were extracted from fresh samples, and 15 from aged samples suggesting that in older samples some compounds became undetectable (Fig. 3).

Figure 4 shows the various classes of compounds detected at the different analysis times. Some compounds were detected at each sampling time. However, ketocarotenoids, ethers, and steroids were only detected in fresh samples (time $=0-5$ days), while aromatic hydrocarbons, amines, and fatty acids were only detected in aged samples (time $=10-15$ days). Some compounds are no longer detectable in aged samples because they evaporate or turn into other compounds. In fact, new molecules appear in aged samples, probably transformed by microbial action.

Only 26 VOCs were considered constituents of human secretions. Compounds were selected on the basis of abundance, and whether they were previously investigated in recent literature. These were used in the analysis of our samples as key markers of the presence of the suspect at the crime scene. Infact, recent research has provided information that supports the feasibility of using hand odor as a means for subject identification and differentiation in forensic investigations. The use of the VOC marker combinations may facilitate the association of individuals to criminal activity, by reducing the number of suspects in a crime (Colón-Crespo et al. 2017). The VOCs that were detected, in accordance with the literature, and could be related to the composition of human secretions, were divided into 11 groups: aliphatic and aromatic hydrocarbons, aldehydes, ketones, alcohols, fatty acids, esters, ethers, amines, steroids, and heterocyclic compounds. The compounds, ordered according to their affiliation in chemical groups, are listed in Table 3.

Some of the VOCs detected, namely keto-carotenoids, terpenes, and terpenoids (Table 4), are not constituents of human secretions because they are likely to be "primary odor" and "tertiary odor." Therefore, after several bibliographic searches, these compounds were considered as contaminants. In particular, Canthaxanthin is a natural pigment belonging to the class of carotenoids. Its presence in tissues is related to the individual's dietary intake, as animals are unable to synthesize them. The coloring of most food, be it vegetarian or otherwise, is the cause for the presence of these classes of compounds in human VOCs (Ytrestøyl et al. 2004; Beaulieu et al. 2013). Terpenes are made up of hydrocarbon chains organized in isoprenic units, while terpenoids are characterized by the introduction of heteroatoms along the hydrocarbon chains. Therefore, this study showed that they possess different functional groups, such as ketones and alcohols. These compounds belong to the classes of dyes, essential oils, and fragrances. In particular, Cedr-8-ene and Camphor are essential oils extracted from Juniperus procera Endl wood, belonging to the family of cypresses that grow in Kenya (Akeng'a and Chhabra 1997).
Table 3 VOCs related to the composition of human secretions

\begin{tabular}{|c|c|}
\hline Chemical functional groups & Compounds \\
\hline \multirow[t]{7}{*}{ Aliphatic hydrocarbons } & Tridecane \\
\hline & Propane \\
\hline & Decane \\
\hline & Cyclohexane, 1,4-dimethyl-2-octadecyl \\
\hline & Dodecane \\
\hline & Undecane \\
\hline & 9-n-Hexylheptadecane \\
\hline Aromatic hydrocarbons & $\begin{array}{l}\text { Naphthalene, decahydro-2,6-dimethyl- } \\
\text { 3-octyl }\end{array}$ \\
\hline \multirow[t]{2}{*}{ Aldehydes } & 14-Octadecenal \\
\hline & Benzaldehyde \\
\hline \multirow[t]{2}{*}{ Ketones } & 3-Dodecylcyclohexanone \\
\hline & 1,4-Naphthoquinone \\
\hline \multirow[t]{3}{*}{ Alcohols } & 2,2-Dimethoxy-ethanol \\
\hline & Ethylhexanol \\
\hline & 1,4-Benzenediol, 2,5-dimethyl \\
\hline Fatty acids & Octadecadienoic acid \\
\hline \multirow[t]{4}{*}{ Esters } & Protoporphyrin IX dimethylester \\
\hline & $\begin{array}{l}\text { Sulfurous acid, cyclohexylmethyl } \\
\text { hexyl ester }\end{array}$ \\
\hline & $\begin{array}{l}\text { 2-Thiopheneacetic acid, } \\
\text { undec-10-enyl ester }\end{array}$ \\
\hline & Propanoic acid, dimethylester \\
\hline Ethers & Octadecane, 1,1-dimethoxy \\
\hline \multirow[t]{2}{*}{ Amines } & Silanamine, N-phenyl \\
\hline & Methyl-3-phenylpyridine \\
\hline Steroids & Tetrahydrocortisone \\
\hline \multirow[t]{2}{*}{ Eterocyclic compounds } & $\begin{array}{l}\text { Ethanone, 2-(4-hydroxy-5,7-dimethylpyrido } \\
{[2,3 \text {-d]pyrimidin-2-ylsulfanyl)-1-(4- }}\end{array}$ \\
\hline & Benzo $[b]$ thiophene, 6-methyl \\
\hline
\end{tabular}

The persistence of a particular substance on the substrate after contact is strictly related to the donor's characteristics, distinguishing them as good or bad donors, depending on the amount of secretion product they release on the substrate they touch (Vanderkolk 2011). It is also related to storage conditions of the samples, the time passed from the contact, and the nature of the substrate (Curran et al. 2007; DeGreeff et al. 2011). In this

Table 4 VOCs related to "primary odor" and "tertiary odor"

\begin{tabular}{lll}
\hline Primary odor & Tertiary odor & \\
\cline { 2 - 3 } Keto-carotenoids & Terpenes & Terpenoids \\
\hline Canthaxanthin & Cedr-8-ene & Beta-methylionone \\
& Thujopsene & Camphor \\
& & Linalylalcohol \\
\hline
\end{tabular}


study, the storage conditions and the time passed from the contact were monitored, eliminating such variables.

This experimental model also analyzed secondary transfer. Donor subjects touched an object, which was placed in contact with gauzes; finally, these were used as samples and analyzed at different time points. Therefore, several compounds could be lost in the transfer from the palms of the hands to the gauze. During secondary transfer, some biological traces as well as some compounds may not be transferred. In this case, we would have only primary transfer (from the subject to the object) and not secondary (from the object to the gauze). The detected compounds were present in traces, in the range of ppb-ppt.

Recent studies suggest that human scent is unique to each person. As previously described, well-trained dogs can positively match the scents of subjects, distinguishing both identical and non-identical twins (Pinc et al. 2011). Dogs have the ability to detect odor concentrations of both organic and inorganic compounds in the range of ppb-ppt. Corroborating our work, previous studies reported that even though each subject does not have the same mixture of VOCs at all times of analysis, dogs were able to match the scent-article with the corresponding subject at all time-points. In the present study, the dog always discriminated the subjects regardless of the contact substrate (two for each subject). Therefore, scent-discriminating dogs demonstrate an advantage over instrumental methods by being able to perform recognition regardless of whether or not the same subject expresses different scent mixtures (Angle et al. 2016). It is important to note that human scents are subjective, and that the dog needs to identify the individual who touched the object at the crime scene. Thus, it is very important to have proper dog training procedures. In Europe, the general method can be divided into two protocols: the tube-retrieving system and the cloth responding system (Prada and Furton 2012).
The professionally trained scent-identification dog is an outstanding biological device for collecting invisible traces at a crime scene. This dog training procedure showed excellent sensitivity (between 99.48 and 100\%) and specificity (between 60 and 100\%), having a positive predictive value (PPV) ranging between 97.94 and $100 \%$ and a negative predictive value (NPV) ranging between 85.71 and $100 \%$ (Table 5).

DNA analysis of the two samples tested in duplicate allowed us to obtain an interpretable profile (12/16 loci) corresponding to the reference (Fig. 5), and three uninterpretable profiles. The DNA concentration on the gauzes was very low, between 0.035 and $0.065 \mu \mathrm{g} / \mathrm{ml}$.

The relationship between the different analyses conducted in this work is that human scent is a good source of VOCs and a good target for canine training. Furthermore, human scent is a latent trace that if sampled in an appropriate manner could allow DNA profiling. The main goal is to identify the perpetrator of the crime, starting with the VOC findings and obtaining a human DNA profile.

\section{Conclusions}

An HS/SPME method was developed, using PDMS/DVB fiber to extract human scent samples after secondary transfer, for the subsequent identification of the VOCs at different time points within a period of 15 days. The GC/MS analysis provided qualitative information about human scent VOC mixtures, which are a good target for canine training. The compounds identified after contact of the gauzes with the scent-articles touched by four different subjects can be divided into 11 groups: aliphatic and aromatic hydrocarbons, aldehydes, ketones, alcohols, fatty acids, esters, ethers, amines, steroids, and heterocyclic compounds. These compounds are constituents of human secretions. Some of these compounds were considered as contaminants, in particular from diet and certain daily activities.

Table 5 Full experimental data on the human scent discrimination by the dogs

\begin{tabular}{|c|c|c|c|c|c|c|c|c|c|c|c|c|}
\hline & Trials & Scent-article & Positive & $\begin{array}{l}\text { True } \\
\text { positive } \\
\text { (TP) }\end{array}$ & $\begin{array}{l}\text { False } \\
\text { positive } \\
\text { (FP) }\end{array}$ & PPV & Negative & $\begin{array}{l}\text { True } \\
\text { negative } \\
\text { (TN) }\end{array}$ & $\begin{array}{l}\text { False } \\
\text { negative } \\
\text { (FN) }\end{array}$ & NPV & Sensitivity & Specificity \\
\hline \multirow[t]{2}{*}{$\overline{M a n} \mathrm{~A}$} & 200 & Ceramic & 194 & 190 & 4 & $97.94 \%$ & 6 & 6 & 0 & $100.00 \%$ & $100.00 \%$ & $60.00 \%$ \\
\hline & 200 & Plastic & 194 & 193 & 1 & $99.48 \%$ & 6 & 6 & 0 & $100.00 \%$ & $100.00 \%$ & $85.71 \%$ \\
\hline \multirow[t]{2}{*}{ Man B } & 200 & Ceramic & 193 & 191 & 2 & $98.96 \%$ & 7 & 6 & 1 & $85.71 \%$ & $99.48 \%$ & $75.00 \%$ \\
\hline & 200 & Plastic & 198 & 198 & 0 & $100.00 \%$ & 2 & 2 & 0 & $100.00 \%$ & $100.00 \%$ & $100.00 \%$ \\
\hline \multirow[t]{2}{*}{ Woman A } & 200 & Treated wood & 192 & 191 & 1 & $99.48 \%$ & 8 & 7 & 1 & $87.50 \%$ & $99.48 \%$ & $87.50 \%$ \\
\hline & 200 & Wax & 200 & 200 & 0 & $100.00 \%$ & 0 & 0 & 0 & & $100.00 \%$ & \\
\hline \multirow[t]{2}{*}{ Woman B } & 200 & Treated wood & 196 & 195 & 1 & $99.49 \%$ & 4 & 4 & 0 & $100.00 \%$ & $100.00 \%$ & $80.00 \%$ \\
\hline & 200 & Wax & 199 & 199 & 0 & $100.00 \%$ & 1 & 1 & 0 & $100.00 \%$ & $100.00 \%$ & $100.00 \%$ \\
\hline
\end{tabular}

$P P V=T P /(T P+F P) ; N P V=T N /(T N+F N) ;$ Sensitivity $=T P /(T P+F N)^{*} 100 ;$ Specificity $=T N /(T N+F P)^{*} 100$ 

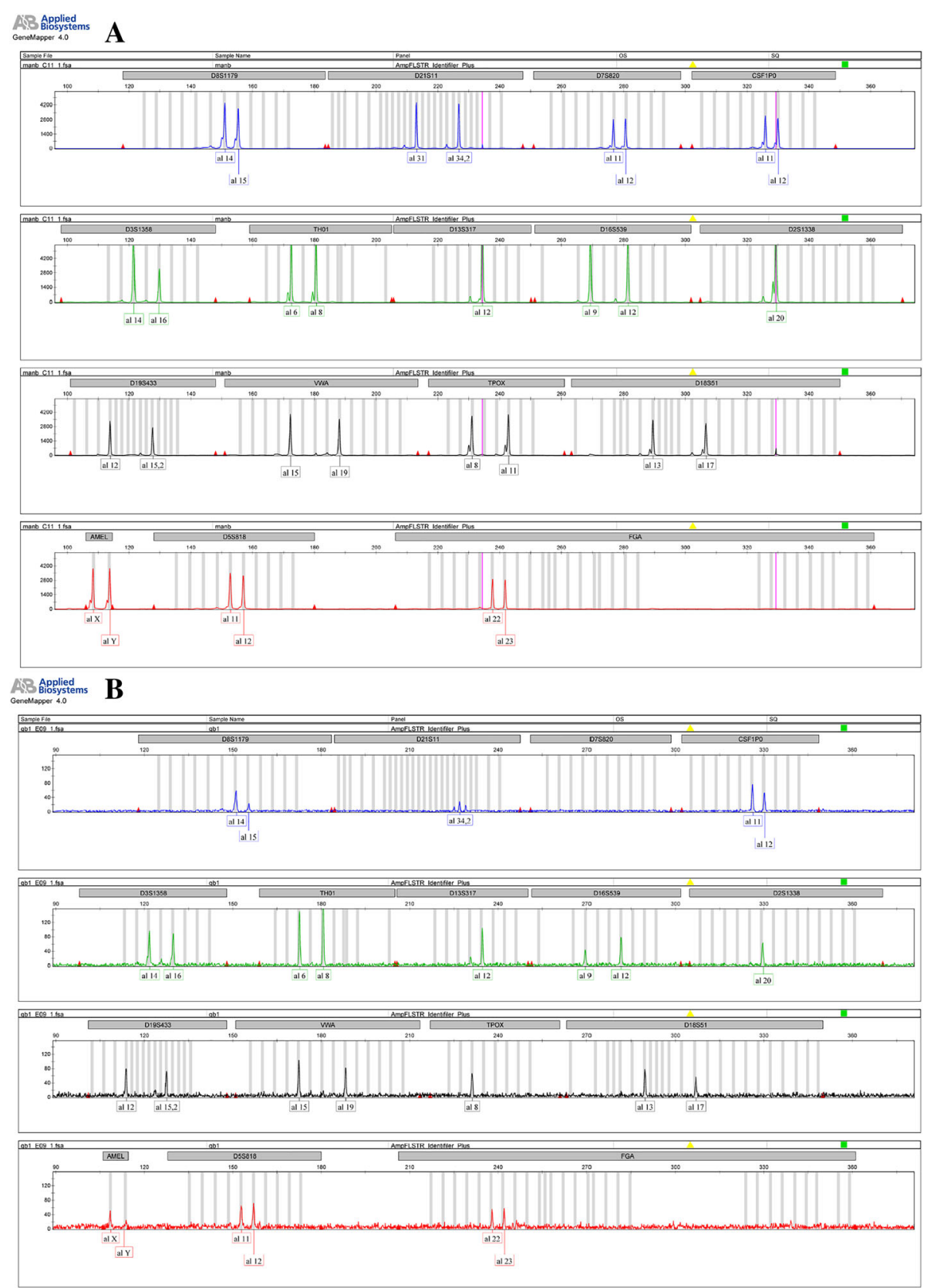

Fig. 5 Electropherograms of the interpretable profile (12/16 loci): reference profile (a) and profile obtained from gauzes (b)

Storage time of human scent samples led to the detection of different VOCs, which were found to have different properties. Some compounds were transferred to the gauze, others were absorbed by the contact substrate, and others evaporated.

The experimental model proposed is sampling the human scent and storing the sample in an appropriate manner, and subsequently explore the analytical technique (GC-MS) and the olfactory capacity of dogs to identify which VOCs are detected by GC-MS from human scent. These trials demonstrate the ability of well-trained dogs to detect human scent and to associate the odor emanation source with the touched objects. Furthermore, this study proposes the use of human scent as a forensic latent trace for DNA profiling. The positive result obtained in the present experimental model could be proposed in a real forensic case, linking the suspect to the crime scene, even if it does not provide any evidence that the suspect was the perpetrator of the crime. Finally, as highlighted in this paper, associating "touch DNA" analysis with human scent evidence could be considered a useful tool to solve a criminal case, increasing the weight of evidence. 
The relationship between the different analyses is that human scent is a good source of VOCs and a good target for canine training. Furthermore, human scent is a latent trace that if sampled in an appropriate manner could allow DNA profiling.

The main limitation of the present study is related to the sample size (two dogs, four humans). The small sample size in this study depends on the type of investigation: a well-trained dog is not easy to find. For this reason, it was not possible to perform statistical tests that normally require a larger sample size, to ensure a representative distribution of the population and to be considered representative of groups of people to whom results will be generalized or transferred. Nevertheless, it is well known that sample size is generally less relevant in qualitative research if explained in the context of the research problem. Moreover, another limitation of the present study is related to the age criteria used to enroll the subjects: indeed, Mitro et al. (2012) described differences in VOCs obtained from human scent according to age criteria. Furthermore, this experimental work aimed to explore the inter-individual differences in VOCs, without analyzing the difference in relation to the different substrates: in fact, the sample was too small to obtain significant information about this.

Finally, this research represents a pilot study to perform further investigation in the future.

\section{Abbreviations \\ El: Electron ionization; GC: Gas chromatographic; GC-MS: Gas chromatography- mass spectrometry; HS/SPME-GC/MS: Headspace/solid-phase microextraction-gas chromatography/mass spectrometry; NIST: National Institute of Standards and Technology; PDMS/DVB: Polydimethylsiloxane/divinylbenzene; STU-100: Scent Transfer Unit 100; VOCs: Volatile organic compounds}

\section{Acknowledgements}

We wish to thank the Scientific Bureau of the University of Catania for language support.

\section{Funding}

The authors received no specific funding for this work.

\section{Availability of data and materials}

All relevant data are inserted in the manuscript. Please contact the author for further data requests.

\section{Authors' contributions}

$V F, G D M, M R, P R, C P, I R, M S$, and FS: conceived the study and participated in its design. $V F, G D M, M R, P F, P R, C P, I R, M S$, and FS: contributed to the conception and design. VF, GM, AM, CZ, MS, and FS wrote the manuscript. $C Z, P R, C P, I R, M S$, and FS drafted the article and revised it critically for intellectual content; VF, GDM, PR, CP, FS: final approval of the version to be published. All authors read and approved the final manuscript.

\section{Ethics approval and consent to participate}

All procedures performed in the study were in accordance with the ethical standards of the University of Foggia and with the 1964 Helsinki Declaration and its later amendments or comparable ethical standards. Informed consent was obtained from all participants. The protocol was approved by the Research Committee (University of Foggia).

Moreover, all experimental procedures were performed in strict accordance with the Italian and EU regulation on animal welfare and were previously approved by the Animal Research Committee of the University of Foggia.

\section{Consent for publication}

The authors declare to have received written consent from all persons involved in this experimental study, to publish the article mentioned above in the Egyptian Journal of Forensic Sciences.

\section{Competing interests}

The authors declare that they have no competing interests.

\section{Publisher's Note}

Springer Nature remains neutral with regard to jurisdictional claims in published maps and institutional affiliations.

\section{Author details}

${ }^{1}$ Department of Biomedical and Biotechnology Sciences, Section of Human Anatomy and Histology, University of Catania, Catania, Sicily, Italy.

${ }^{2}$ Department of Legal, Historical, Economic and Social Sciences, University of Catanzaro, Catanzaro, Italy. ${ }^{3}$ Department of Clinical and Experimental

Medicine, Section of Legal Medicine, University of Foggia, Foggia, Italy.

${ }^{4}$ Forensic Toxicology Sections, "G. Tatarella" Hospital, Cerignola, Foggia, Italy.

${ }^{5}$ Department of Legal Medicine, University of Magna Graecia di Catanzaro, Catanzaro, Italy. "Section of Legal Medicine, "F. Ingrassia" Department, University of Catania, Catania, Italy. ${ }^{7}$ Department of Anatomy, University of Malta, Msida MSD 2080, Malta. ${ }^{8}$ Department of Experimental Medicine, Section of Human Physiology and Unit of Dietetics and Sports Medicine, Università degli Studi della Campania "Luigi Vanvitelli", Naples, Italy. ${ }^{9}$ Department of Medical and Surgical Sciences and Advanced Technologies GF Ingrassia, University of Catania, Via S. Sofia 78, 95123 Catania, Italy.

Received: 13 March 2019 Accepted: 17 June 2019

Published online: 02 July 2019

\section{References}

Akeng'a TA, Chhabra SC (1997) Analysis of the essential oil of Juniperus procera Endl. growing in Kenya. Afr J Med Med Sci 26(1-2):79-81

Angle C, Waggoner LP, Ferrando A, Haney P, Passler T (2016) Canine detection of the volatilome: a review of implications for pathogen and disease detection. Front Vet Sci 3(JUN). https://doi.org/10.3389/fvets.2016.00047

Beaulieu RA, Warwar RE, Buerk BM (2013) Cantaxanthin retinopathy with visual Ioss: a case report and review. Case Rep Ophthalmol Med. https://doi.org/ 10.1155/2013/140901

Bernier UR, Kline DL, Barnard DR, Schreck CE, Yost RA (2000) Analysis of human skin emanations by gas chromatography/mass spectrometry. 2. Identification of volatile compounds that are candidate attractants for the yellow fever mosquito (Aedesaegypti). Anal Chem 72(4):747-756. https://doi.org/10.1021/ ac990963k

Caraballo NI, Mendel J, Holness H, La Salvia J, Moroose T, Eckenrode B, Mills D (2016) An investigation into the concurrent collection of human scent and epithelial skin cells using a non-contact sampling device. Forensic Sci Int 266:148-159. https://doi.org/10.1016/j.forsciint.2016.05.019

Colón-Crespo LJ, Herrera-Hernández D, Holness H, Furton KG (2017) Determination of VOC marker combinations for the classification of individuals by gender and race/ethnicity. Forensic Sci Int 270:193-199

Curran AM, Prada PA, Schoon AA, Almirall JR, Furton KG (2005) Human scent as a biometric measurement. In: Proceedings of SPIE-the International Society for Optical Engineering, vol 5779, pp 398-408. https://doi.org/10.1117/ 12.603820

Curran AM, Ramirez CF, Schoon AA, Furton KG (2007) The frequency of occurrence and discriminatory power of compounds found in human scent across a population determined by SPME-GC/MS. J Chromatogr B Anal Technol Biomed Life Sci 846(1-2):86-97. https://doi.org/10.1016/j.jchromb. 2006.08.039

De Simone S, Maglietta F, Ferrara M, Spagnolo L, Ricci P, De Carlo D, Salerno M, Sessa F, Bertozzi G (2019) Homicide or car accident: the case of the 'guilty' fibre. Med Leg J. https://doi.org/10.1177/0025817219830275

DeGreeff LE, Curran AM, Furton KG (2011) Evaluation of selected sorbent materials for the collection of volatile organic compounds related to human scent using non-contact sampling mode. Forensic Sci Int 209(1-3):133-142. https://doi.org/10.1016/j.forsciint.2011.01.010

Doležal P, Kyjaková P, Valterová I, Urban Š (2017) Qualitative analyses of less-volatile organic molecules from female skin scents by comprehensive 
two dimensional gas chromatography-time of flight mass spectrometry. J Chromatogr A 1505:77-86. https://doi.org/10.1016/j.chroma.2017.04.062

Ensminger JJ, Jezierski T, Mc Culloch M (2010) Scent identification in criminal investigations and prosecutions: new protocol designs improve forensic reliability. SSRN. https://doi.org/10.2139/ssrn.1664766

Ferrara M, Sessa F, Rendine M, Spagnolo L, De Simone S, Riezzo I et al (2019) A multidisciplinary approach is mandatory to solve complex crimes: a case report. Egypt J Forensic Sci 9(1):11. https://doi.org/10.1186/s41935-019-0116-8

Gajjar RM, Kasting GB (2014) Absorption of ethanol, acetone, benzene and 1,2-dichloroethane through human skin in vitro: a test of diffusion model predictions. Toxicol Appl Pharmacol. https://doi.org/10.1016/j.taap.2014.09.013

Goray M, Eken E, Mitchell RJ, van Oorschot RAH (2010) Secondary DNA transfer of biological substances under varying test conditions. Forensic Sci Int Genet 4:62-67. https://doi.org/10.1016/j.fsigen.2009.05.001

Haze S, Gozu Y, Nakamura S, Kohno Y, Sawano K, Ohta H, Yamazaki K (2001) 2-Nonenal newly found in human body odor tends to increase with aging. J Investig Dermatol 116(4):520-524. https://doi.org/10.1046/j.0022202X.2001.01287.x

Hoffman EM, Curran AM, Dulgerian N, Stockham RA, Eckenrode BA (2009) Characterization of the volatile organic compounds present in the headspace of decomposing human remains. Forensic Sci Int 186(1-3):6-13

Intarakumhaeng R, Wanasathop A, Li SK (2018) Effects of solvents on skin absorption of nonvolatile lipophilic and polar solutes under finite dose conditions. Int J Pharm. https://doi.org/10.1016/j.ijpharm.2017.11.042

Kanda F, Yagi E, Fukuda M, Nakajima K, Ohta T, Nakata O (1990) Elucidation of chemical compounds responsible for foot malodour. Br J Dermatol 122(6):771-776. https://doi.org/10.1111/j.1365-2133.1990.tb06265.x

Ladd C, Adamowicz MS, Bourke MT, Scherczinger CA, Lee HC (1999) A systematic analysis of secondary DNA transfer. J Forensic Sci 44:1270-1272

Maglietta F, Sessa F, Albano GD, Bertozzi G, Giugliano P, Vacchiano G et al (2017) Italian mafia: a focus on Apulia mafia with a literature review. Acta Medica Mediterranea 2017(6):947-952. https://doi.org/10.19193/0393-6384_ 2017_6_149

Marchal S, Bregeras O, Puaux D, Gervais R, Ferry B (2016) Rigorous training of dogs leads to high accuracy in human scent matching-to-sample performance. PLoS One 11(2). https://doi.org/10.1371/journal.pone.0146963

Messina A, Bitetti I, Precenzano F, lacono D, Messina G, Roccella M et al (2018) Non-rapid eye movement sleep parasomnias and migraine: a role of orexinergic projections. Front Neurol 9(FEB). https://doi.org/10.3389/fneur. 2018.00095

Mitro S, Gordon AR, Olsson MJ, Lundström JN (2012) The smell of age: perception and discrimination of body odors of different ages. PLoS One 7(5):e38110. https://doi.org/10.1371/journal.pone.0038110

Munk S, Münch P, Stahnke L, Adler-Nissen J, Schieberle P (2000) Primary odorants of laundry soiled with sweat/sebum: influence of lipase on the odor profile. J Surfactant Deterg 3(4):505-515. https://doi.org/10.1007/s11743-000-0150-z

Pandey SK, Kim K-H (2011) Human body-odor components and their determination. TrAC Trends Anal Chem 30(5):784-796. https://doi.org/ 10.1016/j.trac.2010.12.005

Pinc L, Bartoš L, Reslová A, Kotrba R (2011) Dogs discriminate identical twins. PLoS One 6(6). https://doi.org/10.1371/journal.pone.0020704

Pomara C, Gianpaolo DP, Monica S, Maglietta F, Sessa F, Guglielmi G, Turillazzi E (2015) "Lupara Bianca" a way to hide cadavers after mafia homicides. A cemetery of Italian mafia. A case study. Legal Med 17(3):192-197. https://doi.org/10.1016/j.legalmed.2014.12.008

Prada A, Furton KG (2012) Recent advances in solid-phase micro-extraction for forensic applications. In: Comprehensive Sampling and Sample Preparation, vol 3. https://doi.org/10.1016/B978-0-12-381373-2.00117-4

Prada P, Furton KG (2008) Human scent detection: a review of its developments and forensic applications. Rev Cienc Forenses 1:81-87.

Rendine M, Fiore C, Bertozzi G, De Carlo D, Filetti V, Fortarezza P, Riezzo I (2018) Decomposing human blood: canine detection odor signature and volatile organic compounds. J Forensic Sci. https://doi.org/10.1111/1556-4029.13901

Riezzo I, Neri M, Rendine M, Bellifemina A, Cantatore S, Fiore C, Turillazzi E (2014) Cadaver dogs: unscientific myth or reliable biological devices? Forensic Sci Int 244:213-221. https://doi.org/10.1016/j.forsciint.2014.08.026

Schoon A, Haak R (2002) K9 suspect discrimination. Detselig Enterprises Ltd, Canada

Sessa F, Franco S, Picciocchi E, Geraci D, Chisari MG, Marsala G et al (2018) Forensic considerations on violent parasomnias during lifespan. Acta Med Mediterr 34(Special Is):2135-2142. https://doi.org/10.19193/0393-6384-2018-4s-328
Spagnolo L, Bertozzi G, Ferrara M, De Simone S, Ricci P, Salerno M et al (2018) From crime scene investigation to the identification of the cause of death: a muscle-popping case report. Rom J Leg Med 26(4):340-343. https:/doi.org/ 10.4323/rilm.2018.340

Sperandeo R, Maldonato MN, Messina A, Cozzolino P, Monda M, Cerroni F, Valenzano A (2018) Orexinsystem: network multi-tasking. Acta Med Mediterr 34(2):349-356. https://doi.org/10.19193/0393-6384_2018_2_55

Stránský K, Zarevúcka M, Valterová I, Wimmer Z (2006) Gas chromatographic retention data of wax esters. J Chromatogr A 1128:208-219

Urbanová K, Vrkoslav V, Valterova I, Hakova M, Cvacka J (2012) Structural characterization of wax esters by electron ionization mass spectrometry. J Lipid Res 53:204-213

Vanderkolk JR (2011) Examination process. In: Fingerprint Sourcebook Chapter 9 Vass AA (2012) Odor mortis. Forensic Sci Int 222(1-3):234-241

Waring MS, Wells JR (2015) Volatile organic compound conversion by ozone, hydroxyl radicals, and nitrate radicals in residential indoor air: magnitudes and impacts of oxidant sources. Atmos Environ 106:382-391. https://doi.org/ 10.1016/j.atmosenv.2014.06.062

Wickenheiser RA (2002) Trace DNA: a review, discussion of theory, and application of the transfer of trace quantities of DNA through skin contact. J Forensic Sci 47(3):442-450

Ytrestøyl T, Coral-Hinostroza G, Hatlen B, Robb DHF, Bjerkeng B (2004) Carotenoid and lipid content in muscle of Atlantic salmon, Salmo salar, transferred to seawater as $0+$ or $1+$ smolts. Comp Biochem Physiol B: Biochem Mol Biol 138(1):29-40. https://doi.org/10.1016/j.cbpc.2004.01.011

Zeng X -n, Leyden JJ, Lawley HJ, Sawano K, Nohara I, Preti G (1991) Analysis of characteristic odors from human male axillae. J Chem Ecol 17(7):1469-1492. https://doi.org/10.1007/BF00983777

Zeng X-N, Leyden JJ, Spielman Al, Preti G (1996) Analysis of characteristic human female axillary odors: qualitative comparison to males. J Chem Ecol 22(2):237-257. https://doi.org/10.1007/BF02055096

\section{Submit your manuscript to a SpringerOpen ${ }^{\circ}$ journal and benefit from:}

- Convenient online submission

- Rigorous peer review

- Open access: articles freely available online

- High visibility within the field

- Retaining the copyright to your article

Submit your next manuscript at $\boldsymbol{\nabla}$ springeropen.com 